\title{
Prostacyclin Synthesis in Ovine Pulmonary Artery Is Developmentally Regulated by Changes in Cyclooxygenase-1 Gene Expression
}

\author{
Timothy S. Brannon, Amy J. North, Lieselotte B. Wells, and Philip W. Shaul \\ Department of Pediatrics, University of Texas Southwestern Medical Center, Dallas, Texas 75235-9063
}

\begin{abstract}
Prostacyclin ( PGI $_{2}$ ) is a key mediator of pulmonary vasomotor tone during late gestation and in the newborn, and its production in whole lung increases during that period. We investigated the developmental regulation of $\mathbf{P G I}_{2}$ synthesis in ovine intrapulmonary artery (PA) segments from 110 to $115 \mathrm{~d}$ (F1) and 125 to 135 d gestation fetal lambs $(F 2$, term = $144 \mathrm{~d})$ and 1and 4-wk-old newborn lambs (NB1 and NB2). Basal PGI Prose $_{2}$ fourfold from F1 to F2, fourfold from F2 to NB1, and twofold from NB1 to NB2. In all age groups $66-72 \%$ of $\mathrm{PGI}_{2}$ was derived from the endothelium. Similar fold increases in $\mathbf{P G I}_{2}$ were observed with maturation in intact and endothelium-denuded segments. In intact PA from F2, NB1, and NB2, basal PGI synthesis and synthesis maximally stimulated by bradykinin, A23187, or arachidonic acid rose with development in a comparable manner. In contrast, $\mathbf{P G I}_{2}$ synthesis stimulated by exogenous $\mathrm{PGH}_{2}$, the product of cyclooxygenase, was similar at all ages. Immunoblot analyses of PA from F2, NB1, and NB2 revealed that there is a sixfold maturational increase in cyclooxygenase-1 protein; the cyclooxygenase- 2 isoform was not detectable. Cyclooxygenase-1 mRNA abundance in whole lung also rose with development. Thus, $\mathbf{P G I}_{2}$ synthesis in ovine $\mathrm{PA}$ endothelium and vascular smooth muscle increases markedly during late fetal and early newborn life; the increase is due to a rise in cyclooxygenase activity related to enhanced expression of cyclooxygenase-1. We conclude that there is developmental regulation of PA cyclooxygenase-1 gene expression, and that this may be critical to successful cardiopulmonary transition and function in the newborn. (J. Clin. Invest. 1994. 93:2230-2235.) Key words: endothelium • mesenteric artery $\bullet$ prostaglandin $\mathbf{E}_{\mathbf{2}} \bullet$ pulmonary hypertension • vascular smooth muscle
\end{abstract}

\section{Introduction}

Prostacyclin $\left(\mathrm{PGI}_{2}\right)^{1}$ is a key mediator of pulmonary vasomotor tone in the late fetal and early postnatal period. The admin-

Address correspondence to Dr. Philip W. Shaul, Department of Pediatrics, University of Texas Southwestern Medical Center, 5323 Harry Hines Boulevard, Dallas, TX 75235-9063.

Received for publication 27 September 1993 and in revised form 22 December 1993.

1. Abbreviations used in this paper: $\mathrm{COX}$, cyclooxygenase; $\mathrm{F} 1$, fetal lambs at 110-115 d gestation; F2, fetal lambs at 125-135 d gestation; NB1, newborn lambs 1-2 wk of age; NB2, newborn lambs 4 wk of age; $\mathrm{PA}$, intrapulmonary artery; $\mathbf{P G I}_{2}$, prostacyclin; VSM, vascular smooth muscle.

J. Clin. Invest.

(C) The American Society for Clinical Investigation, Inc.

0021-9738/94/05/2230/06 \$2.00

Volume 93, May 1994, 2230-2235 istration of $\mathrm{PGI}_{2}$ causes pulmonary vasodilatation in the fetus and newborn, and vasoconstriction occurs when its endogenous synthesis is inhibited (1-4). In addition, $\mathrm{PGI}_{2}$ plays a major role in successful cardiopulmonary transition at the time of birth $(5,6)$, and it attenuates hypoxic pulmonary vasoconstriction in the neonatal period (7). There is evidence that $\mathrm{PGI}_{2}$ also modulates vascular cell growth in the pulmonary circulation (8-11). Pulmonary $\mathrm{PGI}_{2}$ is primarily synthesized in the endothelium and vascular smooth muscle (VSM) (12).

Studies in a variety of species indicate that the synthesis of $\mathrm{PGI}_{2}$ and other vasodilatory prostaglandins in whole lung increases dramatically during late gestation and in the newborn (13-15). This increase may play an important role in the fall in pulmonary vascular resistance that occurs not only at birth, but also more gradually thereafter, and it may also be involved in maturational changes in pulmonary vessel structure (16). The specific cell source of this developmental increase and the mechanism(s) underlying it are unknown.

The purpose of the present study was to determine the ontogeny of $\mathrm{PGI}_{2}$ synthesis in ovine intrapulmonary arteries (PA) during the late fetal and early newborn period, and to delineate the mechanism(s) underlying the developmental regulation of its synthesis. Based on the findings of previous investigations in whole lung (13-15), we hypothesized that $\mathrm{PGI}_{2}$ synthesis in the PA increases in late gestation and the early postnatal period. In addition to testing this hypothesis, studies were performed to address the following questions: $(a)$ Is the developmental increase in $\mathrm{PGI}_{2}$ synthesis specific to that prostanoid? (b) Is it specific to the PA? (c) Does the developmental increase in $\mathrm{PGI}_{2}$ synthesis occur in pulmonary artery endothelium or VSM? and $(d)$ At what step in the $\mathrm{PGI}_{2}$ synthetic pathway is the developmental increase mediated?

\section{Methods}

Animal model. The lamb has been used extensively in investigations of the role of vasodilatory prostaglandins in the regulation of pulmonary vasomotor tone in the fetus and newborn $(1-5,12,13,17)$. As such, it is an excellent animal model for the in vitro study of the ontogeny of PA PGI ${ }_{2}$ synthesis. In the present investigation, PA segments were obtained from four groups of mixed breed lambs. They were fetal lambs at $110-115$ d gestation (F1, $n=4)$; fetal lambs at $125-135$ d gestation (F2, $n=21$ ), with term being $144 \pm 4 \mathrm{~d}$; newborn lambs $1-2$ wk of age (NB1, $n=12$ ); and newborn lambs 4 wk of age (NB2, $n=15)$. The pregnant ewes used $(n=35)$ were multiparous and had singletons ( $n$ $=22$ ), twins $(n=9)$, or triplets $(n=4)$. Before killing, the animals were housed in the Animal Resources Center of the University of Texas Southwestern Medical Center and were given standard animal chow and water ad lib. The procedures followed in the care and euthanasia of the study animals were approved by the Institutional Review Board for Animal Research.

Arterial segment preparation. The procedures used generally follow those we have previously reported (18). Briefly, the ewe and fetus(es) were euthanized with sodium pentobarbital $(50 \mathrm{mg} / \mathrm{kg})$ given intravenously to the ewe, and the fetuses were delivered by cesarean section. 
The newborn lambs were killed in a similar manner. The lungs were immediately removed and placed in ice-cold phosphate-buffered saline $\left(0.01 \mathrm{M} \mathrm{PO}_{4}, 0.15 \mathrm{M} \mathrm{NaCl}, \mathrm{pH} 7.4\right)$. Further tissue preparation was performed in a cold room at $4^{\circ} \mathrm{C}$. The intrapulmonary arterial tree was rapidly dissected from the lung parenchyma and placed in fresh icecold phosphate-buffered saline. Remaining fatty and connective tissue was removed and the adventitia was grossly dissected from the arteries, taking care not to disrupt the endothelium.

Fourth generation PA were isolated and placed in freshly prepared $\mathrm{Krebs}-\mathrm{Henseleit} \mathrm{buffer} \mathrm{gassed} \mathrm{with} 95 \% \mathrm{O}_{2} / 5 \% \mathrm{CO}_{2}$ at $37^{\circ} \mathrm{C}(19)$. The Krebs-Henseleit buffer contained the following (mM): $4.8 \mathrm{KCl}, 2.0$ $\mathrm{CaCl}_{2}, 1.2 \mathrm{KH}_{2} \mathrm{PO}_{4}, 1.2 \mathrm{MgSO}_{4}, 11.0$ dextrose, $118 \mathrm{NaCl}$, and 25 $\mathrm{NaHCO}_{3}$ at $\mathrm{pH}$ 7.4. Fourth generation arteries were chosen for study in an effort to examine these biochemical mechanisms in freshly obtained intact arterial segments as close to the level of the resistance vessels as possible (19). Segments with wet weights of 1-4 mg were cut, rinsed in fresh oxygenated Krebs-Henseleit buffer, and equilibrated in the oxygenated buffer at $37^{\circ} \mathrm{C}$ for $2 \mathrm{~h}$. In some studies the endothelium was removed by repeated passage of silk suture through the artery lumen. The presence or absence of intact, functional endothelium was confirmed in randomly chosen segments by light microscopy of 5- $\mu \mathrm{m} \mathrm{sec-}$ tions of the arteries, examinations of endothelium-dependent relaxation with acetylcholine, and quantification of CGMP production with acetylcholine stimulation (20). In selected animals, comparably sized mesenteric arteries were also obtained for use in parallel studies.

Third generation PA were also obtained from some animals for use in immunoblot analyses (19). These arteries were chosen to provide sufficient tissue for evaluations of protein abundance in microsomal preparations (see below). Whole lung was also harvested to obtain adequate quantities of poly $(\mathrm{A})^{+}$RNA for Northern analyses (see below). At the time of killing, the third generation arteries and the lung specimens were rapidly dissected and frozen immediately in liquid nitrogen.

Incubations for prostaglandin synthesis. The incubation procedures used were similar to those we have used in previous studies of arteries from fetal and newborn lambs $(18,21,22)$. The segments were placed individually into sealed polypropylene chambers containing 2.0 $\mathrm{ml}$ of oxygenated $\left(\mathrm{PO}_{2}=680 \mathrm{mmHg}\right) \mathrm{Krebs}-\mathrm{Henseleit} \mathrm{buffer}$ at $37^{\circ} \mathrm{C}$ for $1 \mathrm{~h}$. After this preincubation period, the media was replaced with fresh oxygenated Krebs-Henseleit buffer and a 15-120-min incubation was performed at $37^{\circ} \mathrm{C}$. At the end of the incubation, the media was placed into ice-cold tubes containing $100 \mu \mathrm{g}$ of acetylsalicylic acid and was stored at $-20^{\circ} \mathrm{C}$ until the time of assay for $\mathrm{PGI}_{2}$ or $\mathrm{PGE}_{2}$ by radioimmunoassay. The segments were placed in ice-cold $7 \%$ trichloroacetic acid and were stored at $-20^{\circ} \mathrm{C}$ until protein content was determined by a modification of the method of Lowry et al. (23), using bovine serum albumin as the standard. We have demonstrated that under these conditions the prostanoids measured are newly synthesized, and synthesis is linear with time for at least $120 \mathrm{~min}(21)$.

Stimulated prostacyclin synthesis. In experiments designed to determine the reaction in the synthetic cascade that is involved in the developmental regulation of $\mathrm{PGI}_{2}$ synthesis, selected arterial segments were incubated in Krebs-Henseleit buffer alone, indicative of basal (nonstimulated) synthesis, and others were treated with agents that activate the synthetic pathway at various steps. We have previously used this approach to investigate oxygen modulation of PA $\mathrm{PGI}_{2}$ synthesis (18). Incubations were performed in the presence of bradykinin to assess the effects of development on $\mathrm{PGI}_{2}$ synthesis stimulated by receptor-mediated mobilization of arachidonic acid from phospholipids (24). Incubations with the calcium ionophore A23187 were done to determine the effects of maturation on $\mathbf{P G I}_{2}$ synthesis stimulated by an increase in cytosolic-free calcium, which activates arachidonic acid mobilization by a nonreceptor-mediated process (25). Exogenous arachidonic acid was also used to stimulate $\mathrm{PGI}_{2}$ synthesis to reveal if the effect of development is reversed by provision of the precursor in excess (25). Reversal of the maturational effect would be seen if the effect occurs proximal to arachidonic acid in the synthetic cascade, and a lack of reversal would indicate that the mechanism involves changes in cyclooxygenase (COX) and/or $\mathrm{PGI}_{2}$ synthetase activity (25). Lastly, incubations were performed in the presence of $\mathrm{PGH}_{2}$, the product of COX activity and the substrate for $\mathrm{PGI}_{2}$ synthetase, to differentiate between potential developmental effects on the activities of these enzymes (25). Studies of concentration-related responses and time courses of activation of the synthetic cascade were performed preliminarily in PA from F2 lambs. Maximal stimulation was found with bradykinin and $\mathrm{A} 23187$ at $10^{-6} \mathrm{M}$, and with arachidonic acid and $\mathrm{PGH}_{2}$ at $10^{-5} \mathrm{M}$. As a result, these concentrations were used in the experiments performed in the different age groups. Basal and stimulated prostaglandin production were linear with time for $\geq 15 \mathrm{~min}$; ensuing incubations were $15 \mathrm{~min}$ in duration. In all experiments, duplicate segments were studied from four to six animals.

Prostaglandin radioimmunoassays. Samples of incubation media were assayed for the stable metabolite of $\mathrm{PGI}_{2}, 6-k e t o-\mathrm{PGF}_{1 \alpha}$, and for $\mathrm{PGE}_{2}$ by radioimmunoassay as previously reported (18). Briefly, the assay procedure used duplicate aliquots of standard $(0-200 \mathrm{pg})$ and samples put into a mixture of Krebs-Henseleit solution and $0.1 \mathrm{M}$ phosphate-buffered saline with $0.1 \%$ polyvinyl-pyrrolidone (1:1). Antiserum $\left(0.1 \mathrm{~mL}, 1: 4,000\right.$ titer for 6-keto-PGF ${ }_{1 \alpha}$ and 1:14,000 titer for $\left.\mathrm{PGE}_{2}\right)$ and $0.1 \mathrm{~mL}$ of $\left[{ }^{3} \mathrm{H}\right]-6-k e t o-\mathrm{PGF}_{1 \alpha}(12,000 \mathrm{cpm})$ or $\left[{ }^{3} \mathrm{H}\right]-\mathrm{PGE}_{2}$ $(16,500 \mathrm{cpm})$ were added and the tubes were incubated at $4^{\circ} \mathrm{C}$ for 12-18 h. The antisera were the kind gift of Dr. William B. Campbell (Department of Pharmacology and Toxicology, Medical College of Wisconsin, Milwaukee, WI). Bound and free ligand were counted by liquid scintillation spectrometry, and the unknown quantities of prostaglandin were determined from the standard curves generated.

Immunoblot analysis for COX protein. Isolation of membranebound COX was carried out using methods modified from those of Van der Ouderaa et al. (26). Third generation PA were homogenized on ice in $50 \mathrm{mM} \mathrm{KH} \mathrm{PO}_{4}$ buffer containing the following (mM): 250 mannitol, 5 disodium EDTA, 0.3 diethyldithiocarbamate, and 0.1 indomethacin, $\mathrm{pH} 7.8$, using a Polytron blender (Brinkmann Instruments, Westbury, NY). The homogenate was centrifuged at $12,000 \mathrm{~g}$ at $4^{\circ} \mathrm{C}$ for $10 \mathrm{~min}$, and the supernatant was centrifuged at $110,000 \mathrm{~g}$ at $4^{\circ} \mathrm{C}$ for $2 \mathrm{~h}$. The pellet was resuspended in ice-cold $50 \mathrm{mM} \mathrm{KH_{2 }} \mathrm{PO}_{4}$ buffer containing $0.1 \mathrm{mM}$ diethyldithiocarbamate and $1 \%$ Tween-20 and was ultrasonically disrupted (Branson Ultrasonics, Chicago, IL). The protein content of the microsomal preparation was determined by the method of Bradford (27) using bovine serum albumin as the standard.

SDS-PAGE was performed with 7\% acrylamide by the method of Laemmli et al. (28), and the proteins were electrophoretically transferred to nitrocellulose filters overnight. The nitrocellulose filters were blocked for $1 \mathrm{~h}$ in buffer containing the following (mM): $100 \mathrm{NaCl}, 20$ $\mathrm{NaH}_{2} \mathrm{PO}_{4}$, and $80 \mathrm{Na}_{2} \mathrm{HPO}_{4}$ (PBS, pH 7.5) with $1 \%$ Tween-20 and 5\% dried milk and then incubated with 1:1,000 ovine COX antiserum (Cayman Chemical Co., Ann Arbor, MI) for $1 \mathrm{~h}$ at room temperature. This rabbit anti-sheep polyclonal antiserum recognizes both isoforms of COX (COX-1 and COX-2) (29). COX-1 is purportedly the constitutive isoform, and COX-2 is inducible and is thought to have a role in inflammatory processes $(29,30)$. After incubation with primary antiserum, the nitrocellulose filters were washed in PBS with $1 \%$ Tween-20 and incubated for $1 \mathrm{~h}$ with a 1:10,000 dilution of an anti-rabbit Ig antibody-horseradish peroxidase conjugate raised in donkey (Amersham Corp., Amersham, UK). The filters were washed in PBS with Tween-20 and the bands for COX were visualized by chemiluminescence (ECL Western Blotting Analysis System; Amersham) and quantitated by densitometry. Additional immunoblots were performed with antiserum specific for COX-2 (Oxford Biomedical Research, Inc., Oxford, MI). Purified COX-1 and COX-2 were used as positive controls. Three independent experiments were performed using samples from separate groups of animals.

Northern analysis for COX $m R N A$. Total cellular RNA was obtained and purified from the lungs by a single extraction method with an acid guanidinium thiocyanate-phenol-chloroform mixture (31). The total RNA was subjected to oligo-dT affinity chromatography to obtain poly-A(+) RNA (32). The poly-A(+) RNA (5-15 $\mu \mathrm{g}$ ) was size 
fractionated on $1.0 \%$ agarose formaldehyde gels and transferred to nylon membranes. The RNA was cross-linked to the membranes by ultraviolet irradiation. After prehybridization, the membranes were hybridized overnight at $42^{\circ} \mathrm{C}$ in the presence of a random-primed ${ }^{32} \mathrm{P}$-labeled COX-1 cDNA probe (Cayman Chemical Co.). After hybridization, the blots were washed and autoradiography was performed. Northern analysis was also performed for the housekeeping gene malate dehydrogenase using a $0.5-\mathrm{kb}$ random-primed ${ }^{32} \mathrm{P}$-labeled $\mathrm{cDNA}$ probe to verify equivalent RNA stability and loading between samples (33). Three independent experiments were performed using samples from separate groups of animals.

Statistical analysis. ANOVA with Neuman-Keuls post hoc testing was used to compare mean values between more than two groups. Nonparametric ANOVA was used when indicated. Single comparisons between two groups were performed with paired and nonpaired Student's $t$ tests. Significance was accepted at the 0.05 level of probability. All results are expressed as mean \pm SEM.

\section{Results}

Basal prostaglandin synthesis. The ontogeny of basal $\mathrm{PGI}_{2}$ synthesis in PA and mesenteric artery is shown in Fig. 1. $\mathrm{PGI}_{2}$ synthesis in PA increased fourfold from F1 to F2, an additional fourfold from F2 to NB1, and another twofold from NB1 to NB2, yielding a 32-fold increase from early third trimester to the late newborn period. In the mesenteric artery there was no difference in $\mathrm{PGI}_{2}$ synthesis in the four age groups.

The ontogeny of $\mathrm{PGE}_{2}$ synthesis is depicted in Fig. 2. In PA, $\mathrm{PGE}_{2}$ synthesis increased fourfold from $\mathrm{F} 1$ to $\mathrm{F} 2$, but it then fell from F2 to NB1 to levels comparable to F1. PA PGE synthesis was similar in NB1 and NB2. A comparable developmental pattern was observed in the mesenteric artery.

The effects of endothelium removal on $\mathrm{PGI}_{2}$ synthesis in PA from F2, NB1, and NB2 lambs are shown in Fig. 3. Removal of the endothelium resulted in a $70 \%$ decrease in $\mathrm{PGI}_{2}$ synthesis in $\mathrm{F} 2$, a $72 \%$ decrease in NB1, and a $66 \%$ decrease in NB2. In the segments denuded of endothelium there was a fourfold increase in $\mathrm{PGI}_{2}$ synthesis between $\mathrm{F} 2$ and $\mathrm{NB} 1$ and

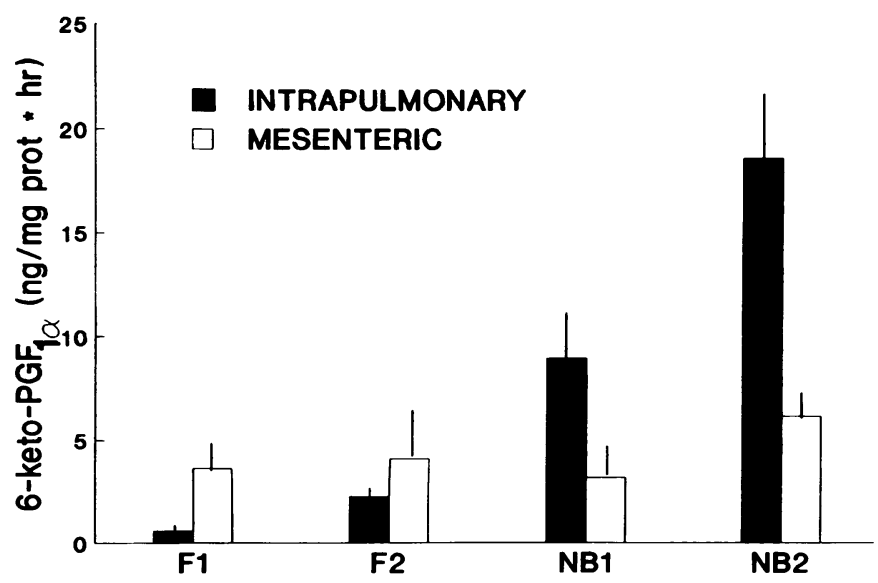

Figure 1. Ontogeny of $\mathrm{PGI}_{2}$ synthesis in intrapulmonary and mesenteric arteries. Arterial segments were obtained from fetal lambs at 110-115 (F1) and 125-135 d gestation (F2) and from newborn lambs at 1-2 (NB1) and $4 \mathrm{wk}$ of age (NB2). Segments were incubated for 120 min, and PGI $_{2}$ (6-keto-PGF ${ }_{1 \alpha}$ ) synthesis was measured by radioimmunoassay. Values are mean \pm SEM for duplicate segments from four to six lambs in each group. For intrapulmonary, F1 $<$ F2 $<$ NB1 $<$ NB2 (ANOVA).

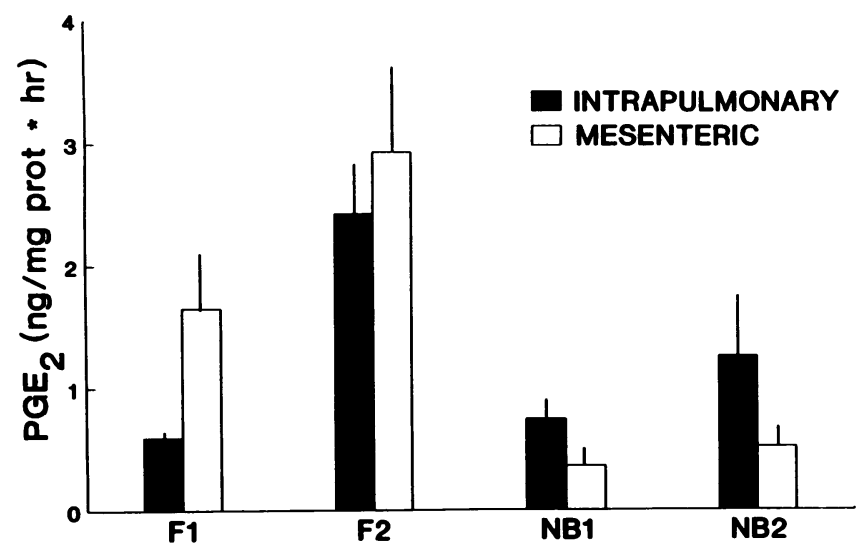

Figure 2. Ontogeny of $\mathrm{PGE}_{2}$ synthesis in intrapulmonary and mesenteric arteries. Segments were incubated for $120 \mathrm{~min}$, and $\mathrm{PGE}_{2}$ synthesis was measured by radioimmunoassay. Values are mean \pm SEM for duplicate segments from four to six lambs in each group. For both intrapulmonary and mesenteric, F1 $<$ F2 $>$ NB1 = NB2 (ANOVA).

another threefold increase between NB1 and NB2, paralleling the developmental rises demonstrated in the intact segments.

Stimulated $\mathrm{PGI}_{2}$ synthesis. To investigate the mechanism underlying the developmental increase in $\mathrm{PA} \mathrm{PGI}{ }_{2}$ synthesis, segments from F2, NB1, and NB2 were incubated in the presence of agents that cause stimulation of the synthetic pathway at various steps. In these experiments, basal synthesis rose $122 \%$ from F2 to NB1 and $64 \%$ from NB1 to NB2 (Fig. 4). Synthesis maximally stimulated by bradykinin (Fig. 4, top) increased $82 \%$ from $\mathrm{F} 2$ to $\mathrm{NB} 1$ and $84 \%$ from NB1 to NB2, paralleling the increases in basal synthesis. Synthesis maximally stimulated by A23187 (Fig. 4, middle) increased $89 \%$ from F2 to NB1 and 54\% from NB1 to NB2, also in parallel with the developmental increases observed in basal synthesis. Arachidonic acid-stimulated synthesis (Fig. 4, bottom) rose $53 \%$ from $\mathrm{F} 2$ to $\mathrm{NB} 1$ and $93 \%$ from NB1 to NB2, and these



Figure 3. Effect of endothelium removal on $\mathrm{PGI}_{2}$ synthesis in intrapulmonary arteries. Arterial segments were obtained from fetal lambs at 125-135 d gestation (F2) and from newborn lambs at 1-2 (NB1) and $4 \mathrm{wk}$ of age (NB2). The endothelium was removed, the segments were incubated for $120 \mathrm{~min}$, and $\mathrm{PGI}_{2}\left(6-\mathrm{keto}^{-} \mathrm{PGF}_{1 \alpha}\right)$ synthesis was measured by radioimmunoassay. Values are mean \pm SEM for duplicate segments from four lambs in each group. ${ }^{*} P<0.05$ vs. with endothelium, $\uparrow P<0.05$ vs. F $2, \Psi P<0.05$ vs. NB1. 


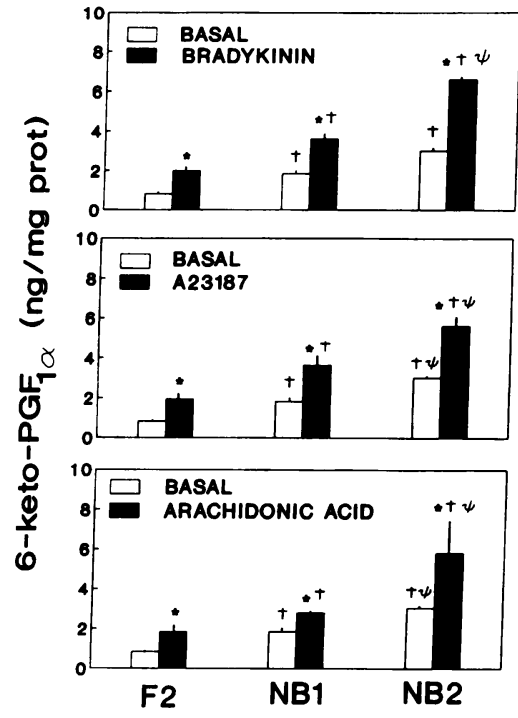

Figure 4. Effect of development on $\mathrm{PGI}_{2}$ synthesis stimulated by bradykinin, A23187, or arachidonic acid. Segments were incubated in the absence of exogenous stimulation ( $b a$ sal) or in the presence of $10^{-6} \mathrm{M}$ bradykinin,


$\mathrm{M}$ arachidonic acid for 15 min, and $\mathrm{PGI}_{2}$ (6keto- $\left.P G F_{1 \alpha}\right)$ synthesis was measured by radioimmunoassay. Values are mean \pm SEM for duplicate segments from four lambs in each group. ${ }^{*} P<0.05$ vs. basal, $\dagger P<0.05$ vs. F2, $\Psi P<0.05$ vs. NB1.

maturational increases were also comparable to the changes noted in basal synthesis.

In a second series of experiments, concomitant determinations of basal and $\mathrm{PGH}_{2}$-stimulated $\mathrm{PGI}_{2}$ synthesis were made. In these studies basal synthesis increased 4.2-fold from $\mathrm{F} 2$ to NB1 and 1.9-fold from NB1 to NB2 (Fig. 5). In contrast to the findings for basal synthesis and for stimulation with bradykinin, A23187, or arachidonic acid (Fig. 4), there were no differences between F2, NB1, and NB2 in synthesis maximally stimulated by $\mathrm{PGH}_{2}$.

COX protein expression. Maturational changes in $\mathrm{COX}$ protein expression in PA from $\mathrm{F} 2, \mathrm{NB} 1$, and NB2 lambs are depicted in Fig. 6. In the representative immunoblot shown, the antiserum used recognizes both COX-1 and COX-2, which are of comparable size ( $70 \mathrm{kD})(29)$. COX protein abundance increased progressively from F2 to NB1 to NB2. Quantitative densitometry from three independent experiments concurred with these observations, revealing that the abundance of COX

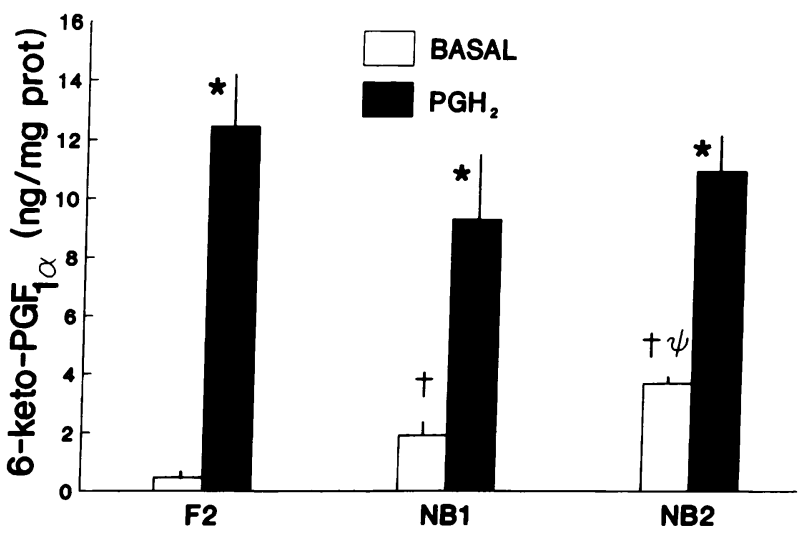

Figure 5. Effect of development on $\mathrm{PGI}_{2}$ synthesis stimulated by $\mathrm{PGH}_{2}$. Segments were incubated in the absence of exogenous stimulation (basal) or in the presence of $10^{-5} \mathrm{M} \mathrm{PGH}_{2}$ for $15 \mathrm{~min}$, and $\mathrm{PGI}_{2}$ (6-keto- $P G F_{1 \alpha}$ ) synthesis was measured by radioimmunoassay. Values are mean \pm SEM for duplicate segments from four lambs in each group. ${ }^{*} P<0.05$ vs. basal, $\uparrow P<0.05$ vs. F2, $\Psi P<0.05$ vs. NB1.

\section{F2 NB1 NB2}
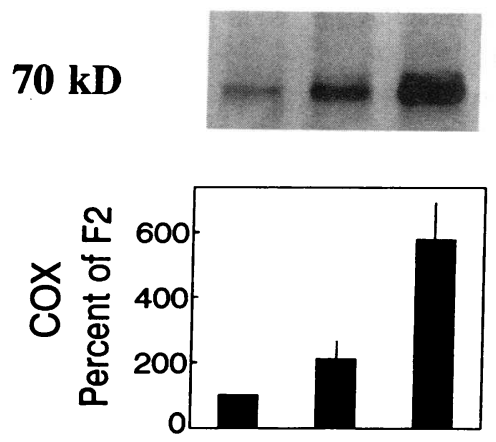

Figure 6. Immunoblot analysis for $\mathrm{COX}$ in intrapulmonary arteries from $\mathrm{F} 2, \mathrm{NB} 1$, and NB2 lambs (top). The antiserum used recognizes both COX-1 and COX2 . The results are representative of three independent experiments using samples from separate groups of animals. Summary data for quantitative densitometry for the three experiments is given in the

lower panel. Mean \pm SEM values are depicted for protein abundance expressed as the percentage of abundance of $F 2$.

protein increased 2.3-fold from F2 to NB1 and another 2.5-fold from NB1 to NB2. Immunoblots specifically for COX-2 did not detect that isoform in PA from any age group $(n=3$, data not shown), indicating that the developmental increase is primarily in COX-1.

COX mRNA expression. Maturational changes in COX-1 mRNA expression in F2, NB1, and NB2 lung are shown in Fig. 7. A single $2.8-\mathrm{kb}$ species was identified. COX-1 mRNA was minimally detectable in $\mathrm{F} 2$, and it increased progressively in abundance in NB1 and NB2.

\section{Discussion}

In this study we have demonstrated that there is a 32 -fold increase in $\mathrm{PGI}_{2}$ synthesis in ovine PA during the third trimester and the early postnatal period. In contrast, there is no change in $\mathrm{PGI}_{2}$ synthesis in comparably sized mesenteric arteries. In both the $\mathrm{PA}$ and mesenteric arteries, $\mathrm{PGE}_{2}$ synthesis rises during late gestation, but it then falls in the newborn period. These observations indicate that $\mathrm{PGI}_{2}$ synthesis in the PA is developmentally regulated in a manner that is unique to that vascular bed and also to that prostanoid.

The findings in the PA confirm our previous results in this species (22). The observed developmental increase in PA PGI synthesis is consistent with the findings of Omini et al. (34), who reported that angiotensin-induced $\mathrm{PGI}_{2}$ synthesis in perfused rabbit lungs is greater in the newborn compared with the

\section{F2 NB1 NB2}

2.8 kb-

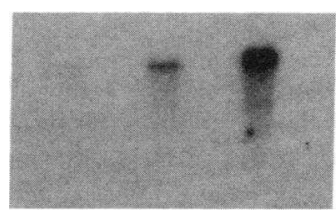

MDH-
Figure 7. Northern analysis for COX-1 using poly $(\mathrm{A})^{+}$RNA from lungs of $F 2$, NB1, and NB2 lambs. The same blot was probed for the housekeeping gene, malate dehydrogenase. A single species was identified for COX1 at $2.8 \mathrm{~kb}$. These results are representative of three independent experiments using samples from separate groups of animals. 
fetus. In addition, the late fetal increase in $\mathrm{PA} \mathrm{PGE}_{2}$ synthesis is consistent with results in both bovine and ovine lung homogenates $(14,15)$. Furthermore, studies in rabbit lung homogenates have shown that $\mathrm{PGE}_{2}$ synthesis from arachidonic acid increases during gestation to a maximum near term, and it then decreases during the early postnatal period (15), closely mimicking the observed rise and fall in ovine PA $\mathrm{PGE}_{2}$ synthesis.

We have also determined whether the developmental increase in $\mathrm{PA} \mathrm{PGI}_{2}$ synthesis occurs in the endothelium or in the VSM. Endothelium removal resulted in comparable deductions (66-72\%) in $\mathrm{PGI}_{2}$ synthesis in PA from all age groups. Considering the relative masses of the endothelium and VSM, such a dramatic fall in synthesis after denudation indicates that the majority of $\mathrm{PGI}_{2}$ synthesis occurs in the endothelium of both fetal and newborn arteries. This extends our previous observations in ovine fetal pulmonary arteries (21). Furthermore, because the developmental increase in $\mathrm{PGI}_{2}$ synthesis was observed in both the intact and denuded segments, it occurs in both the endothelium and the VSM.

In addition, we have identified the step in the synthetic cascade that is involved in the developmental regulation of PA $\mathrm{PGI}_{2}$ synthesis. First, we examined the effects of development on $\mathrm{PGI}_{2}$ synthesis maximally stimulated with bradykinin, which acts via receptor-mediated processes (24). The maturational increase in $\mathrm{PGI}_{2}$ production seen in the absence of exogenous stimulation (basal) was preserved in segments stimulated with bradykinin. These results indicate that the effect of development is not due to changes in the production of a local receptor agonist, and that it must be more distal in the synthetic pathway.

We next evaluated the stimulation of $\mathrm{PGI}_{2}$ synthesis by non-receptor-mediated activation of arachidonic acid mobilization using A23187 (25). The degree of enhancement of basal $\mathrm{PGI}_{2}$ synthesis seen with maturation was mimicked in segments maximally stimulated with A23187, indicating that the effect of development on $\mathrm{PGI}_{2}$ synthesis does not involve alterations in arachidonic acid mobilization. This conclusion is supported by the observation that segments incubated with excess arachidonic acid also exhibited increases in $\mathrm{PGI}_{2}$ production with development that were comparable to the changes in basal synthesis. As such, the effect of maturation on $\mathrm{PGI}_{2}$ synthesis must be at the level of $\mathrm{COX}$ or $\mathrm{PGI}_{2}$ synthetase.

The possible effects of development on the activities of these enzymes in the PA were differentiated by stimulating $\mathrm{PGI}_{2}$ synthesis with exogenous $\mathrm{PGH}_{2}$, the product of $\mathrm{COX}$ and the substrate for $\mathrm{PGI}_{2}$ synthetase (25). $\mathrm{PGI}_{2}$ synthesis stimulated by $\mathrm{PGH}_{2}$ was similar in all age groups, indicating that the maturational increase in basal synthesis is not related to enhanced $\mathrm{PGI}_{2}$ synthetase activity, but to increased COX activity. These findings are in agreement with the observations of Printz and coworkers (13) that COX activity in ovine lung homogenates increases with development in the late fetus and newborn, whereas $\mathrm{PGI}_{2}$ synthetase activity does not. In addition, our results indicating that PA PGE $_{2}$ synthesis declines in the newborn and the corroborating observations by Powell and Solomon (15) in rabbit lung suggest that there is a fall in $\mathrm{PGH}_{2}-\mathrm{PGE}_{2}$ isomerase activity postnatally.

The activity of COX is dependent not only on the provision of arachidonic acid as substrate, but also on the availability of molecular oxygen, hydroperoxides, and heme $(26,35,36)$. The abundance of the enzyme protein is also critical in many systems because COX undergoes self-catalyzed inactivation (36), with a half-life $<10 \mathrm{~min}(37,38)$. In the present study, $\mathrm{PGI}_{2}$ synthesis was determined at high levels of in vitro oxygenation, excluding the availability of molecular $\mathrm{O}_{2}$ as a factor; maturational changes in hydroperoxide and heme abundance were not evaluated. Immunoblot analyses revealed that there is a marked developmental increase in COX protein abundance in the ovine PA and that it is primarily the COX-1 isoform. COX-1 and COX-2 are both expressed in vascular cells (29), the former being purportedly constitutive in nature and the latter inducible and possibly involved in inflammatory processes $(29,30)$. Experiments were not performed to examine the inducibility of COX-2 during development. In the present study steady state levels of COX-1 mRNA were also found to rise dramatically in the lung with maturation. Because the endothelium and VSM are the primary sources of $\mathrm{PGI}_{2}$ in the lung, it is most likely that the increases in COX-1 mRNA occur in those cell types. As such, it is concluded that COX-1 gene expression is developmentally regulated in PA, and that this may involve changes in transcription rate or mRNA stability.

There are important physiological ramifications of the findings in this study. The developmental increase in PA COX expression in the fetus may optimize the capacity for rapid $\mathrm{PGI}_{2}$-mediated pulmonary vasodilatation immediately at the time of birth in response to oxygenation, ventilation, and shear stress $(39,40)$. The existence of the latter mechanism is supported by the observation of Abman and Accurso (41) that partial compression of the ductus arteriosus of the late gestation fetal lamb causes a rapid increase in pulmonary blood flow, which is attenuated by $\mathrm{COX}$ inhibition. It has also been demonstrated that lung $\mathrm{PGI}_{2}$ content increases after cesarean section delivery of late gestation lambs (42). In addition, the continued maturational rise in COX expression in the newborn and the resulting increase in $\mathrm{PGI}_{2}$ synthesis may contribute to the normal fall in pulmonary vascular resistance, which also occurs more gradually in the early postnatal period (43). Furthermore, because $\mathrm{PGI}_{2}$ attenuates VSM growth $(10,11)$ and the maturational increase in its synthesis parallels the decline in pulmonary arterial muscularity from fetal to postnatal life (16), developmental changes in $\mathrm{PGI}_{2}$ synthesis may also play a role in normal maturational alterations in pulmonary vessel structure. However, caution may be warranted in the direct extrapolation of the present observations to in vivo processes because these studies were performed in vitro in conductance and not resistance vessels.

Our observations also have potential pathophysiological implications because diminished $\mathrm{PGI}_{2}$ synthesis has been associated with certain forms of pulmonary hypertension. Although lung $\mathrm{PGI}_{2}$ content is not decreased in an ovine model of perinatal pulmonary hypertension specifically induced by ductus compression for 9-12 d (42), prolonged inhibition of prostaglandin synthesis induces pulmonary hypertension and alterations in lung vessel morphology in adult sheep (8). In addition, chronic hypoxic pulmonary hypertension in adult rats and the structural changes that accompany it are negated by the administration of agents that stimulate vascular $\mathrm{PGI}_{2}$ synthesis (9). Furthermore, it has been demonstrated that PA $\mathrm{PGI}_{2}$ synthesis is attenuated in newborn calves with chronic hypoxic pulmonary hypertension (44). When these findings are considered along with the present results indicating that the normal maturational rise in $\mathrm{PA} \mathrm{PGI}_{2}$ synthesis is related to increased COX expression, it is postulated that there may be 
conditions in which attenuated $\mathrm{COX}$ expression contributes to pulmonary hypertension in the newborn.

In summary, we have demonstrated that $\mathrm{PGI}_{2}$ synthesis in ovine PA increases markedly during late fetal and early newborn life. The increase in $\mathrm{PGI}_{2}$ is specific to the PA, it occurs in both the endothelium and VSM, and it is due to a rise in COX activity related to enhanced expression of the COX-1 isoform. We conclude that there is a developmental increase in PA COX-1 gene expression, and that this may be critical to successful cardiopulmonary transition and function in the newborn.

\section{Acknowledgments}

We are indebted to Ms. Melody Farrar, Ms. Jo Smith, and Mr. Kevin Horning for their skilled technical assistance and to Ms. Marilyn Dixon for preparing this manuscript.

This work was supported by Basil O'Connor Award No. 5-FY910623 from the March of Dimes Birth Defects Foundation; by Grant-inAid 90R-113 from the American Heart Association, Texas Affiliate; and by U.S. Public Health Service grants HD-30276, HD-08783, and HD-24971.

\section{References}

1. Green, R., J. Rojas, and H. Sundell. 1979. Pulmonary vascular response to prostacyclin in fetal lambs. Prostaglandins. 18:927-934.

2. Leffler, C. W., and J. R. Hessler. 1979. Pulmonary and systemic vascular effects of exogenous prostaglandin $\mathrm{I}_{2}$ in fetal lambs. Eur. J. Pharmacol. 54:37-42.

3. Lock, J. E., P. M. Olley, and F. Coceani. 1980. Direct pulmonary vascular responses to prostaglandins in the conscious newborn lamb. Am. J. Physiol. 238:H631-H638.

4. Lock, J. E., P. M. Olley, S. Soldin, and F. Coceani. 1980. Indomethacin-induced pulmonary vasoconstriction in the conscious newborn lamb. Am. J. Physiol. 238:H639-H651.

5. Davidson, D. 1988. Pulmonary hemodynamics at birth: effect of acute cyclooxygenase inhibition in lambs. J. Appl. Physiol. 64:1676-1682.

6. Leffler, C. W., T. L. Tyler, and S. Cassin. 1978. Effect of indomethacin on pulmonary vascular response to ventilation of fetal goats. Am. J. Physiol. 235:H346-H351.

7. Tyler, T., R. Wallis, C. Leffler, and S. Cassin. 1975. The effects of indomethacin on the pulmonary vascular response to hypoxia in the premature and mature newborn goat. Proc. Soc. Exp. Biol. Med. 150:695-698.

8. Meyrick, R., M. E. Niedermeyer, M. L. Ogletree, and K. L. Brigham. 1985. Pulmonary hypertension and increased vasoreactivity caused by repeated indomethacin in sheep. J. Appl. Physiol. 59:443-452.

9. Rabinovitch, M., M. Mullen, H. C. Rosenberg, K. Maruyama, H. O’Brodovich, and P. M. Olley. 1988. Angiotensin II prevents hypoxic pulmonary hypertension and vascular changes in rat. Am. J. Physiol. 254:H500-H508.

10. Owen, N. E. 1985. Prostacyclin can inhibit DNA synthesis in vascula smooth muscle cells. In Prostaglandins, Leukotrienes, and Lipoxins. J. M. Bailey, editor. Plenum Press, New York. 193-204.

11. Huttner, J. J., E. T. Gwebu, R. V. Panganamala, G. E. Milo, and D. G. Cornwell. 1977. Fatty acids and their prostaglandin derivatives: inhibitors of proliferation in aortic smooth muscle cells. Science (Wash. DC). 197:289-291.

12. Rabinovitch, M., N. Boudreau, G. Vella, F. Coceani, and P. M. Olley 1989. Oxygen-related prostaglandin synthesis in ductus arteriosus and other vascular cells. Pediatr. Res. 26:330-335.

13. Printz, M. P., R. A. Skidgel, and W. F. Friedman. 1984. Studies of pulmonary prostaglandin biosynthetic and catabolic enzymes as factors in ductus arteriosus patency and closure. Evidence for a shift in products with gestational age. Pediatr. Res. 18:19-24.

14. Pace-Asciak, C. R. 1977. Prostaglandin biosynthesis and catabolism in the developing sheep lung. Prostaglandins. 13:649-660.

15. Powell, W. S., and S. Solomon. 1978. Biosynthesis of prostaglandins and thromboxane $\mathrm{A}_{2}$ by fetal lung homogenates. Prostaglandins. 15:351-365.

16. Reid, L. M. 1979. The pulmonary circulation: remodeling in growth and disease. Am. Rev. Respir. Dis. 119:531-546.

17. Skidgel, R. A., W. F. Friedman, and M. P. Printz. 1983. Prostaglandin biosynthetic activities of isolated fetal lamb ductus arteriosus, other blood vessels, and lung tissue. Pediatr. Res. 18:12-18.

18. Shaul, P. W., W. B. Campbell, M. A. Farrar, and R. R. Magness. 1992.
Oxygen modulates prostacyclin synthesis in ovine fetal pulmonary arteries by an effect on cyclooxygenase. J. Clin. Invest. 90:2147-2155.

19. Levin, D. L., A. M. Rudolph, M. A. Heymann, and R. H. Phibbs. 1976. Morphological development of the pulmonary vascular bed in fetal lambs. Circulation. 53:144-151.

20. Shaul, P. W., M. A. Farrar, and T. M. Zellers. 1992. Oxygen modulates endothelium-derived relaxing factor production in fetal pulmonary arteries. $\mathrm{Am}$. J. Physiol. 262:H355-H364.

21. Shaul, P. W., M. A. Farrar, and R. R. Magness. 1992. Prostacyclin synthesis and stimulation of cyclic AMP production in ovine fetal vasculature: heterogeneity in pulmonary and systemic arteries. Dev. Pharmacol. Ther. 18:89-99.

22. Shaul, P. W., M. A. Farrar, and R. R. Magness. 1993. Oxygen modulation of pulmonary artery prostacyclin synthesis is developmentally regulated. $\mathrm{Am}$. J. Physiol. 265:H621-H628.

23. Lowry, O. H., N. J. Rosebrough, A. L. Farr, and R. J. Randall. 1951. Protein measurement with the Folin phenol reagent. J. Biol. Chem. 193:265275.

24. McIntyre, T. M., G. A. Zimmerman, K. Satoh, and S. M. Prescott. 1985. Cultured endothelial cells synthesize both platelet-activating factor and prostacyclin in response to histamine, bradykinin, and adenosine triphosphate. J. Clin Invest. 76:271-280.

25. Smith, W. L. 1986. Prostaglandin biosynthesis and its compartmentation in vascular smooth muscle and endothelial cells. Annu. Rev. Physiol. 48:251-262.

26. Van der Ouderaa, F. J., M. Buytenhek, D. H. Nugteren, and D. A. Van Dorp. 1977. Purification and characterisation of prostaglandin endoperoxide synthetase from sheep vesicular glands. Biochim. Biophys. Acta. 487:315-331.

27. Bradford, M. M. 1976. A rapid and sensitive method for the quantitation of microgram quantities of protein utilizing the principle of protein-dye binding. Anal. Biochem. 72:248-254.

28. Laemmli, U. K. 1970. Cleavage of structural proteins during the assembly of the head of bacteriophage T4. Nature (Lond.). 227:680-685.

29. Hla, T., and K. Neilson. 1992. Human cyclooxygenase-2 cDNA. Proc. Natl. Acad. Sci. USA. 89:7384-7388.

30. O'Banion, M. K., V. D. Winn, and D. A. Young. 1992. cDNA cloning and functional activity of a glucocorticoid-regulated inflammatory cyclooxygenase. Proc. Natl. Acad. Sci. USA. 89:4888-4892.

31. Chomczynski, P., and N. Sacchi. 1987. Single-step method of RNA isolation by acid guanidinium thiocyanate-phenol-chloroform extraction. Anal. Biochem. 162:156-159.

32. Aviv, H., and P. Leder. 1972. Purification of biologically active globin messenger RNA by chromatography on oligothymidilic acid-cellulose. Proc. Natl. Acad. Sci. USA. 69:1408-1412.

33. Grant, P. M., J. Tellam, V. L. May, and A. W. Strauss. 1986. Isolation and nucleotide sequence of a cDNA clone encoding rat mitochondrial malate dehydrogenase. Nucleic Acids Res. 14:6053-6066.

34. Omini, C., T. Vigano, A. Marini, R. Pasargiklian, M. Fano, and M. A Maselli. 1983. Angiotensin II: a releaser of $\mathrm{PGI}_{2}$ from fetal and newborn rabbit lungs. Prostaglandins. 25:901-910.

35. Ohki, S., N. Ogino, S. Yamamoto, and O. Hayaishi. 1979. Prostaglandin hydroperoxidase, an integral part of prostaglandin endoperoxide synthase from bovine vesicular gland microsomes. J. Biol. Chem. 254:829-836.

36. Marshall, P. J., R. J. Kulmacz, and W. E. M. Lands. 1987. Constraints on prostaglandin biosynthesis in tissues. J. Biol. Chem. 262:3510-3516.

37. Fu, J. Y., J. L. Masferrer, K. Seibert, A. Raz, and P. Needleman. 1993. The induction and suppression of prostaglandin $\mathrm{H}_{2}$ synthase (cyclooxygenase) in human monocytes. J. Biol. Chem. 265:16737-16740.

38. Fagan, J., and A. L. Goldberg. 1986. Inhibitors of protein and RNA synthesis cause a rapid block in prostaglandin production at the prostaglandin synthase step. Proc. Natl. Acad. Sci. USA. 83:2771-2775.

39. Heymann, M. A., and J. I. E. Hoffman. 1984. Persistent pulmonary hypertension syndromes in the newborn. In Pulmonary Hypertension. E. K. Weir and J. T. Reeves, editors. Futura, New York. 45-71

40. Van Grondelle, A., G. S. Worthen, D. Ellis, M. M. Mathias, R. C. Murphy, R. J. Strife, J. T. Reeves, and N. F. Voelkel. 1984. Altering hydrodynamic variables influences $\mathrm{PGI}_{2}$ production by isolated lungs and endothelial cells. J. Appl. Physiol. 57:388-395.

41. Abman, S. H., and F. J. Accurso. 1989. Acute effects of partial compression of ductus arteriosus on fetal pulmonary circulation. Am. J. Physiol. 257:H626-H634.

42. Abman, S. H., and K. R. Stenmark. 1992. Changes in lung eicosanoid content during normal and abnormal transition in perinatal lambs. Am. J. Phys iol. 262:L214-L222.

43. Heymann, M. A., and S. J. Soifer. 1989. Control of the fetal and neonatal pulmonary circulation. In Pulmonary Vascular Physiology and Pathophysiology. E. K. Weir and J. T. Reeves, editors. Marcel Dekker, New York. 33-50.

44. Badesch, D. B., E. C. Orton, L. M. Zapp, J. Y. Westcott, J. Hester, N. F Voelkel, and K. R. Stenmark. 1989. Decreased arterial wall prostaglandin production in neonatal calves with severe chronic pulmonary hypertension. Am. J. Respir. Cell Mol. Biol. 1:489-498. 